\title{
Teaching Sustainable Design Using BIM and Project-Based Energy Simulations
}

\author{
Zhigang Shen *, Wayne Jensen, Timothy Wentz and Bruce Fischer \\ The Durham School of Architectural Engineering and Construction, \\ The University of Nebraska-Lincoln, 113 NH, Lincoln, NE 68588-0500, USA; \\ E-Mails: wayne.jensen@unl.edu (W.J.) ; twentz1@unl.edu (T.W.) ; bfischer2@unl.edu (B.F.) \\ * Author to whom correspondence should be addressed; E-Mail: shen@unl.edu; \\ Tel.: +1-402-472-9470; Fax: +1-402-472-4087.
}

Received: 11 July 2012; in revised form: 4 August 2012/ Accepted: 20 August 2012/

Published: 27 August 2012

\begin{abstract}
The cross-disciplinary nature of energy-efficient building design has created many challenges for architecture, engineering and construction instructors. One of the technical challenges in teaching sustainable building design is enabling students to quantitatively understand how different building designs affect a building's energy performance. Concept based instructional methods fall short in evaluating the impact of different design choices on a buildings' energy consumption. Building Information Modeling (BIM) with energy performance software provides a feasible tool to evaluate building design parameters. One notable advantage of this tool is its ability to couple 3D visualization of the structure with energy performance analysis without requiring detailed mathematical and thermodynamic calculations. Project-based Learning (PBL) utilizing BIM tools coupled with energy analysis software was incorporated into a senior level undergraduate class. Student perceptions and feedback were analyzed to gauge the effectiveness of these techniques as instructional tools. The findings indicated that BIM-PBL can be used to effectively teach energy-efficient building design and construction.
\end{abstract}

Keywords: energy-efficient; building information modeling; project-based learning 


\section{Introduction}

Sustainability is increasingly being emphasized in higher education in response to the rising cost of utilities and the increased emphasis on sustainable development [1,2]. In many engineering disciplines, course contents have been modified or new courses developed to incorporate sustainability [3]. Buildings, which consume approximately 40 percent of the total generated energy in the United States, have significant potential for lowering US energy consumption, if properly designed and constructed. In architecture, engineering and construction (AEC) education, great effort has been made toward incorporating sustainability into existing or new courses [4]. Sustainable building design and construction (SBDC), an important component of AEC education, is gradually being incorporated into most AEC curricula.

The interdisciplinary and complex nature of SBDC makes instruction and learning of this subject a challenge. The challenge is reflected by both pedagogical and technical issues. Traditional concept-driven pedagogical methods have definite limitations in preparing students to deal with complex, ill-structured, multidisciplinary problems [5], such as sustainable building systems and the impact of different design choices on a building's energy consumption. The greatest technical challenge to successfully teaching SBDC is to enable students to quantitatively understand how differences in building design affect that building's energy performance. The authors discovered only a few published articles where approaches to incorporating SBDC into a pedagogical program of instruction were discussed.

In this paper, the authors report a case study on their experiences and conclusions drawn from combining two innovative tools, Building Information Modeling (BIM) coupled with energy analysis software, and project-based learning (PBL), into a college course to teach sustainable building design and construction. An undergraduate elective course was used as a pedagogical laboratory where two instructional techniques were experimentally incorporated into a sustainable building design and construction course. These techniques included: (1) a synthesis of lecture-based and project-based learning methods [6-8]; and (2) 3D Building Information Modeling (BIM) incorporating energy efficiency software.

PBL has been proposed to supplement concept-based learning methods by many engineering educators and practitioners [6-9]. In PBL, actual projects are used to provide students with realistic ill-defined problems in settings [5] similar to what they will encounter in real-world situations.

BIM, an emerging 3D semantic design tool [10], has been integrated into AEC education at many institutions [11-13]. Newly developed BIM-based energy analysis tools [14] make a preliminary evaluation of a building's energy use easier, faster, and more accessible to the academic community [15]. One significant advantage of using BIM in teaching SBDC is its ability to couple 3D visualization with energy performance analysis. This coupled ability enables students to quickly identify and evaluate the impact of design and construction changes on a building's energy performance without having to complete detailed mathematical and thermodynamics calculations.

The combined capacity of 3D BIM modeling with a building energy analysis program provides a method of teaching project-based SBDC while addressing the shortcomings of concept-based engineering courses by providing nearly simultaneous energy efficiency analysis. The primary goal of this paper is to share instructional experience and to prompt discussion on this or other effective 
methods of teaching SDBC. The objectives of this paper are: (1) to provide information concerning an integrated, BIM-PBL course developed to teach building design and construction; (2) to report findings on learning outcomes and student perceptions of using BIM-PBL with energy analysis software as a teaching tool.

\section{Related Works}

\subsection{Project-Based Learning (PBL)}

PBL was incorporated as the central teaching and learning technique of this class to better prepare students for dealing with the interdisciplinary nature of energy-efficient building design and construction in actual scenarios. Although there are many definitions of PBL, there are several common themes from the constructivism view of learning [9,16,17]: (1) anchor learning activities to realistic context to add learning motivation; (2) provide authentic and ill-defined problems to prepare students to deal with reality; (3) involve students in constructive investigations and open-end discussions; and (4) learn by hands-on doing.

Many researchers suggest that PBL is an effective teaching and learning method especially in upper-level courses and courses dealing with cross-disciplinary complex subjects $[18,19]$. In many engineering disciplines, capstone and/or senior design courses use PBL or a similar learning environment [20].

The value of PBL in sustainability education has been recognized by many educators [21-23]. PBL takes the form of a charrette for many design majors. Walker and Seymour [23] introduced this method to measure the learning effectiveness of the PBL in their class. Brunetti et al. [21] reported their findings when using PBL to enhance the awareness of sustainability in a context of social, economic and environmental issues. Brundiers [24] stressed the importance of using real-world scenarios in teaching sustainability.

\subsection{BIM in Building Design, Construction and Sustainability Education}

Most sustainability related software uses some type of mathematical model to conduct energy analysis [11,12] and lifecycle analysis of building cost [13]. Recently, significant improvements in data interoperability among BIM and other software platforms [25] have made BIM-based energy analysis feasible in a classroom setting. Sustainability has been identified as an important aspect of construction education [26]. A recent survey by Becerik-Gerber et al. [4] revealed that almost $60 \%$ of all AEC programs in the United States currently incorporate BIM into their curriculum. The survey also revealed that nearly $40 \%$ of all construction programs incorporate some function of BIM to teach one or more aspects of sustainability. Most schools that do not currently use BIM for instructional purposes have plans to introduce at least some aspects of BIM into their curriculum. Given the results of the survey, academicians seem to agree that BIM has significant value as a teaching tool within AEC curricula.

Research on uses of BIM in AEC education has become more prolific in recent years. Many research focused on how to teaching students to utilize BIM to improve project management [27], and to improve design [28] and estimating [29]. There is an ongoing discussion regarding the pros and cons 
of offering stand-alone BIM courses versus incorporating BIM into existing courses [30,31]. It appears that most AEC programs are using BIM in a variety of classes after some basic skills are acquired by students through a stand-alone course. Other academicians question whether BIM should be offered as an upper level (junior or senior) class or at the freshman level [32].

However, in terms of BIM in sustainability, the majority of existing literature focuses on the research side on how to use BIM to predict building energy consumption [33-35]. Despite the fact that $40 \%$ AEC programs have been using BIM in teaching some aspects of sustainability [4], three are very few existing literature dedicated to the classroom teaching aspects on how to implement building energy analysis in AEC curriculum using BIM and energy simulation tools. Despite the recognized effectiveness of PBL, very few papers were found on discussion of how to incorporate PBL into teaching building energy simulations on BIM platform.

The literature review identified a need for further research into methods of effectively incorporating BIM into SDBC instruction. One method of doing this is by combining BIM with PBL. This paper seeks to contribute to the knowledge of using the BIM-PBL combination as an instructional tool especially in regard to teaching sustainable design and construction.

\section{The Course of BIM and Energy-Efficient Buildings}

\subsection{Course Background}

A newly developed BIM course served as the laboratory for this research. One of the course outcomes was for students to become familiar with three different BIM software packages (Revit Architecture, Revit MEP, and Autodesk Ecotect ${ }^{\circledR}$ ) [11] in order to use the software to conduct "what-if" sustainability analyses near the end of the semester. Typical functions of Ecotect ${ }^{\circledR}$, a BIM based sustainability analysis software, were used in relation to their applicability to classroom instruction. A real-world commercial building was used as the term project. Students' solutions were evaluated to determine if students had achieved desired outcomes and class objectives. Feedback from students was collected in the form of a survey to help quantify various aspects of learning, including students' perceptions concerning the effectiveness of BIM coupled with energy efficiency software.

The BIM course developed by the authors was offered as a mixed graduate/undergraduate technical elective in a Construction Management curriculum. This course was designed with the primary objective of exposing undergraduate senior-level students to BIM design with energy efficiency analysis. A secondary objective was to assist enrolled graduate students with finding BIM-based research projects related to sustainability. One measured outcome was the ability of students to correctly complete preliminary energy load calculations based upon a 3D BIM model designed by each student. This outcome required the students to develop a basic understanding of a building's structure, envelope, and its Mechanical-Electrical-Plumbing (MEP) systems.

A total of twelve students enrolled in this class, including seven senior undergraduate students and five graduate students. The undergraduate students were required to have completed mechanical/plumbing and electrical (MEP) courses before enrolling. All five graduate students had at least limited knowledge of building MEP, structural and envelope systems. 


\subsection{The Course Modules}

Course content was divided into three major learning modules and a project module, based on the course objectives and functions of the three software packages. The four modules, as summarized in Figure 1, include: Module 1: 3D Building Modeling; Module 2: 3D HVAC and Zone Modeling; Module 3: Building Energy Consumption Analysis using BIM Models; and Module 4: The Term Project Module.

Figure 1. Summary of the Course Modules.

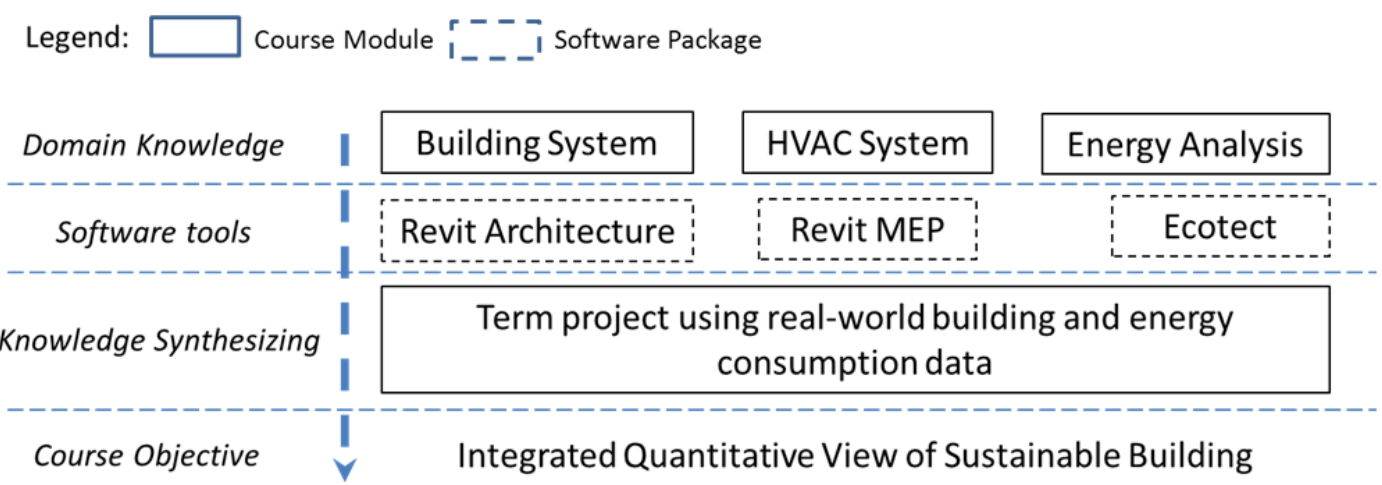

In Module 1, students learned to use Revit Architecture ${ }^{\circledR} 2011$ to create 3D architectural models of a residential building of their own design. The learning objective of this module was for students to learn how to create an architectural BIM rendering using different building envelope types and materials. Students learned the configurations of various wall systems, insulation materials and cladding. At the end of this module, the expected outcome was for students to be able to model a fully functional residential building.

In Module 2, students learned to use Revit MEP ${ }^{\circledR} 2011$ to create various types of heating, venting, air-conditioning (HVAC) and plumbing systems for the residence they had designed in Module 1. Students also learned to create spaces and zones for heating and cooling. After completing this module, the expected outcome was for students to have developed an integrated understanding of building mechanical systems with an enhanced understanding of the spatial relationships among building systems.

In Module 3, students learned to use Autodesk Ecotect ${ }^{\circledR} 2011$ to analyze the energy consumption of the residence they created in Module 1 and Module 2. After completing Module 3, students were expected to have acquired the ability to conduct building energy analysis and to have developed basic concepts concerning the factors that most significantly influence residential energy consumption.

In Module 4, students applied the knowledge and software skills developed in the previous three modules to an actual project. In this real-world project, students utilized their acquired knowledge and skills to conduct various what-if design analyses. This exercise allowed students to develop a solid understanding of how different design options affect a building's energy consumption. The expected outcome of this module was for students to develop critical thinking skills about real-world problems associated with energy-efficient design. There were no right or wrong answers. Instead actual energy consumption data was provided for the building. Comparisons between the building's energy 
consumption as modeled in BIM and its actual energy usage provided feedback allowing students to understand the complexity of real-world situations.

\subsection{The Course Schedule}

Course assignments were organized into three major parts as shown in Figure 2. The first BIM model (Project 1) required eight weeks where students were expected to learn how to use Revit Architecture and Revit MEP to design a ranch-style, single family residence, which included architectural design, mechanical, electrical, and plumbing design and building layout.

Figure 2. Course timeline and major assignments.

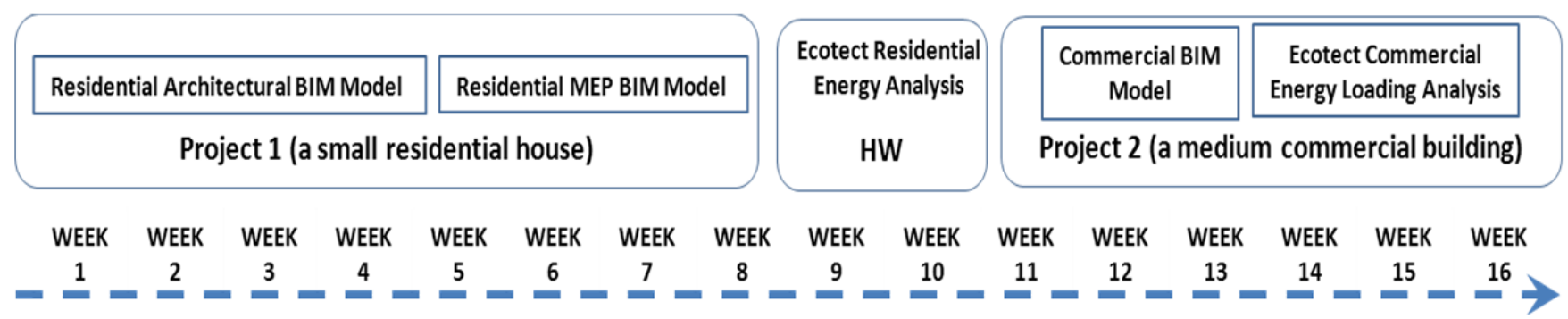

The technical details of how to use the software were taught using in-class tutorials, exercises, assignments, and short tutorials on YouTube. Tutorials on YouTube proved to be a valuable resource which enabled students to become familiar with the technical details of Revit at their own pace. However, it was necessary for the instructor to provide the big picture before students were able to use YouTube effectively. For example, the instructor explained the concept of stack walls before encouraging students to access YouTube for instructions on how to incorporate a stack wall into the model.

Students were expected to learn the basic skills of model creation for architectural and MEP components in the simpler residential project. The residential project was followed by an energy analysis assignment, which used the model each student had created during the residential project. After completing the residential project and the energy analysis homework, students were expected to have acquired basic knowledge and skills concerning how to create a BIM model and how to use that model to calculate the energy load of a building.

Students were allocated five weeks to complete the term project (Project 2). Here students created an architectural and space model of an existing building in the local community. Energy consumption over a four year period was then provided so students could compare the energy usage calculated from the model to the energy consumed by the actual building. As a critical part of this project, students were asked to analyze discrepancies between their modeled results and the actual energy consumption. This analysis was included as part of student's final report and presentation. Students developed critical thinking skills by relating their class assignments, where scope was well-defined, to this realistic scenario involving an actual project, where the scope was more complex and ill-defined. The contrast between the models completed in class and actual energy use was expected to increase students' awareness of the complexity and ambiguities associated with working on real-world projects. 


\subsection{Learning Outcome Assessment}

Quizzes, assignments, graded homework and presentations were used to provide frequent assessment of student learning. Figure 3a illustrates some samples of students' typical submissions for the residential project (Project 1). Figure 3b illustrates typical results for the commercial project (Project 2).

As a part of their analysis, students were required to develop suggestions to reduce the energy consumption of their original models by $30 \%$. Ecotect ${ }^{\circledR}$ provides convenient functions which allow student to try many alternatives, such as different building materials, layouts, number of occupants, and other pertinent variables. Using these functions, almost all students achieved the $30 \%$ energy reduction objective by substituting different building configurations or different materials. To complete this part of the exercise, students were required to model alternatives based upon a number of 'what-if' scenarios.

Figure 3. (a) Architectural and Mechanical/Electrical/Plumbing (MEP) modeling; (b) Ecotect building energy analysis.

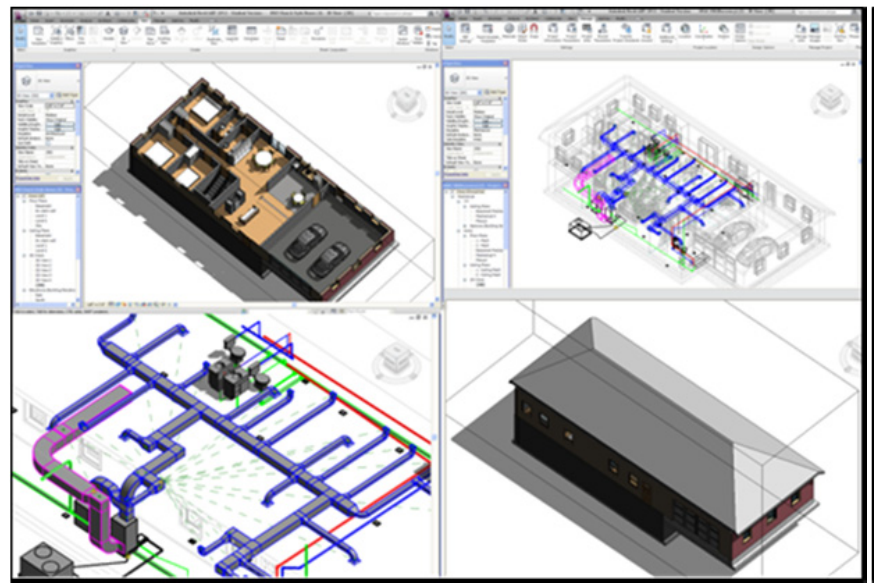

(a)

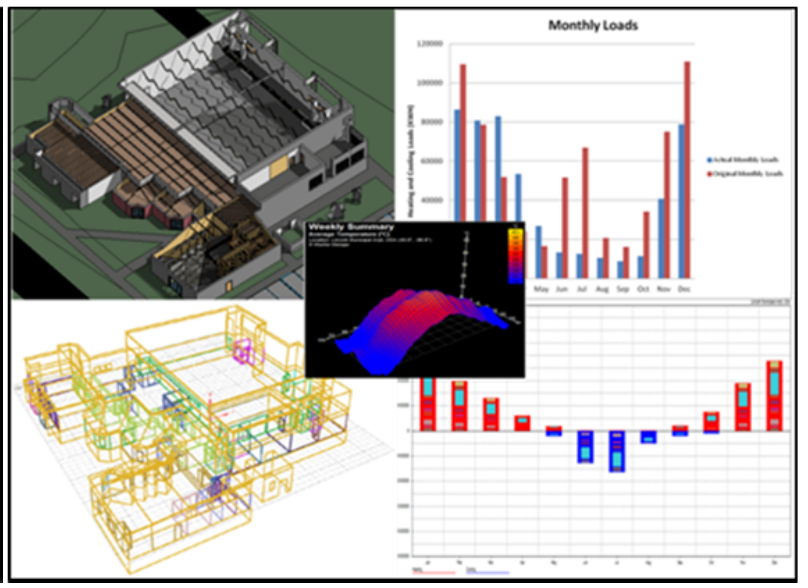

(b)

\section{Results and Discussion}

Table 1 and Table 2 demonstrate outcomes from the final project reports.

One part of the final project was to compare the simulated annual energy consumption to four years of actual energy consumption and to analyze the results for any discrepancies between the actual and estimated quantities.

Most students' simulated energy consumption was 30\%-50\% higher than the annual energy consumption of the actual building. Table 1 lists possible causes for this discrepancy identified by the students. This exercise introduced students to the complexity and some of the limitations of building energy simulation.

Table 2 is a summary of proposed solutions where students were asked to devise methods to reduce the building's energy consumption by $30 \%$. The proposed solutions were based on multiple what-if scenarios. Simulations represent a significant departure from the way sustainability is taught in concept based courses. The most significant change is that students receive almost immediate feedback from 
their design changes while using the Ecotect ${ }^{\circledR}$ software. They are then free to explore other options, where they also receive almost immediate feedback. In a concept based setting, feedback is received through written evaluation of homework, which is often returned days or weeks later. Software provides almost immediate feedback and enables students to explore other options based upon that information.

Table 1. Factors identified by students which might cause a difference between simulated and actual energy consumption.

\begin{tabular}{|c|c|c|}
\hline ID & Factors & Remark \\
\hline 1 & Operation hours & Simulated hours may not match the actual hours \\
\hline 2 & Office equipment & Simulated office equipment may be different from actual \\
\hline 3 & $\begin{array}{l}\text { Number } \quad \text { of } \\
\text { occupants }\end{array}$ & Not sure what are the actual number of occupants \\
\hline 4 & Zone & Identified zoning issue during site visit \\
\hline 5 & Indoor temperatures & $\begin{array}{l}\text { Actual indoor temperature might be different from the simulated } \\
\text { one }\end{array}$ \\
\hline 6 & Air Infiltrations & Identified issue during the site visit \\
\hline 7 & Weather data & Annual degree days might vary \\
\hline 8 & Building's age & $\begin{array}{l}\text { Roof, wall, window and door conditions cannot be set in } \\
\text { simulation }\end{array}$ \\
\hline 9 & Building category & $\begin{array}{l}\text { Difficult to find a good match of predefined building category in } \\
\text { Ecotect }\end{array}$ \\
\hline
\end{tabular}

Table 2. Typical solutions proposed by students to reduce $30 \%$ of original energy consumptions through what-if simulations.

\begin{tabular}{ll}
\hline No. & Typical solutions \\
\hline 1 & Change insulation on walls and roofs \\
2 & Reduce infiltration rate \\
3 & Adding more zones to have better control of indoor temperatures \\
4 & Use higher quality windows and doors \\
$5 *$ & Reduce hours of building operation \\
\hline
\end{tabular}

* May not be an appropriate solution.

Near the end of the class, a survey was administered to obtain student feedback about the instructional techniques used. Table 3 summarizes questions 1-3 and 8-15. Results shown in Figure 4 for those questions indicated that students were overwhelmingly positive about the effectiveness of using BIM and energy simulation software as a method of learning sustainable building design (Questions 1-3).

The results from Question 9 indicated that students were less certain that using the energy efficiency software enabled them to better understand how heating/cooling loads were calculated. The results from Question 10 indicated that one student did not perceive that analyzing energy consumption data from an actual building could be useful for indicating possible problems with simulation used during the design process. Survey results for Question 11-12 were designed to gain better understanding of students' perceptions regarding the value of a BIM-based course compared to 
concept based sustainability courses. Although the overall feedback was still positive, a broader spectrum of opinions was evident. It was also surprising that students appeared to be more slightly comfortable using BIM to evaluate architectural systems than using BIM to evaluate MEP systems. 
Table 3. The survey questions used in this paper (full version is attached as Appendix A).

\begin{tabular}{l} 
ID \\
\hline 1 Creating BIM models (Architectural) helped me to better understand architectural systems \\
(wall, foundation, floor, roof, etc.). \\
2 Creating BIM models (MEP) helped me to better understand MEP systems (air terminals, \\
duct, AHU, condenser, plumbing, drainage systems, etc.). \\
3 Ecotect ${ }^{\circledR}$ helped me to better understand how building systems affect building \\
energy consumption. \\
Modeling MEP helped me to better understand whole building systems including \\
architectural design. \\
Ecotect thermal analysis using a 3D BIM model helped me to better understand how \\
heating/cooling loads are calculated. \\
$10 \begin{array}{l}\text { Using an existing building and actual energy consumption data in the second project enabled } \\
\text { me to better understand problems with simulations. }\end{array}$ \\
11 I feel I could learn similar knowledge in a different class without doing architectural \\
BIM modeling, \\
12 I feel I could learn similar knowledge in a different class without doing MEP BIM modeling. \\
13 Which of the following is an accurate description of your prior knowledge of Arch systems? \\
14 Which of the following is an accurate description of your prior knowledge of MEP systems? \\
15 Which of the following is an accurate description of your prior knowledge of factors affecting \\
building energy consumption?
\end{tabular}

Figure 4. Survey results of Questions 1-3 and Questions 8-12.

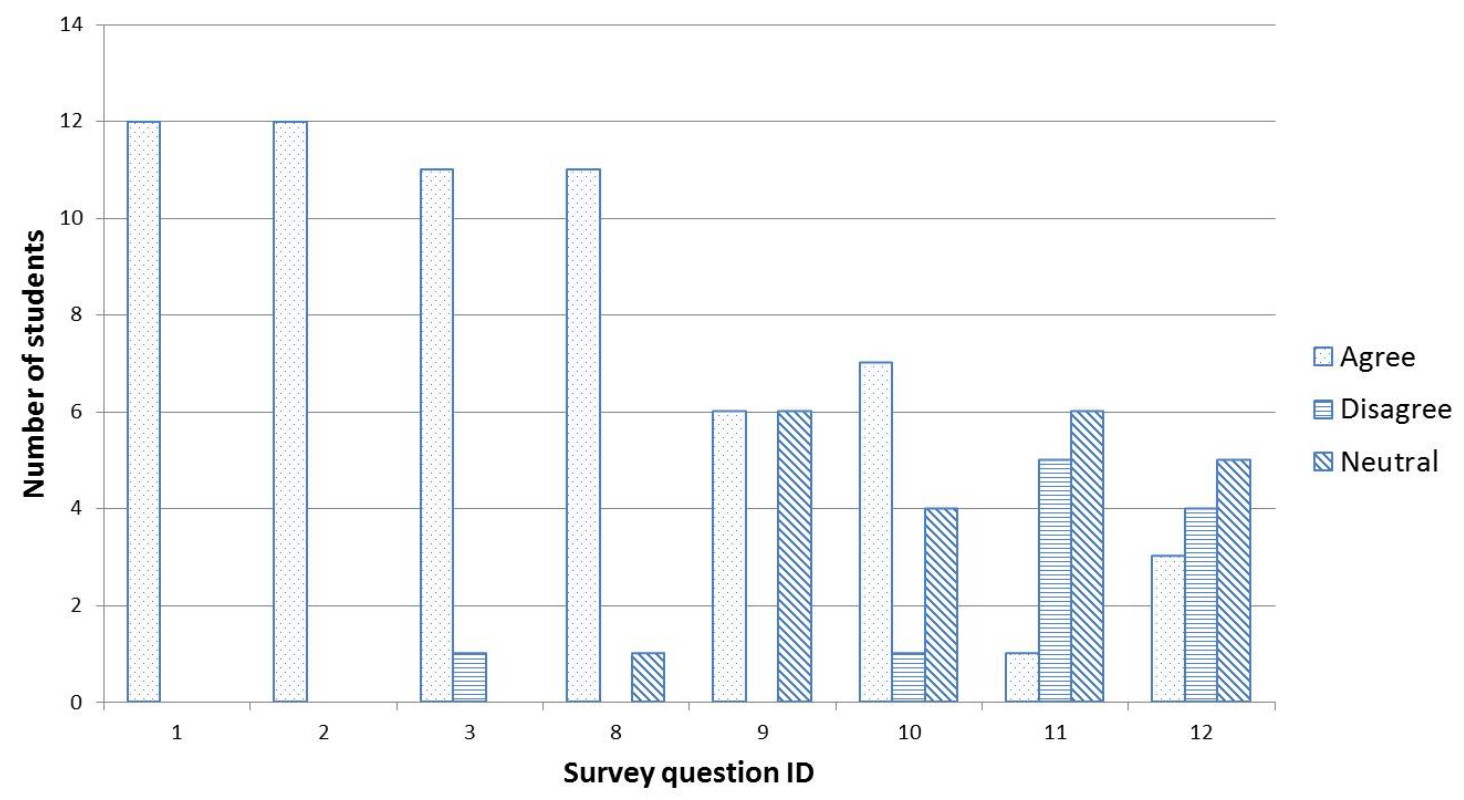

Figure 5 contains the survey results of students' response concerning their previous knowledge of three major building design and construction areas, which corresponds to Question 13-15 on the survey. Figure 5 illustrates that the majority of the students appeared quite confident of their background knowledge in architectural and MEP systems, while the majority were less confident of their background knowledge of factors affecting building energy consumption. While students appeared slightly less confident of their MEP systems knowledge versus their architectural systems 
knowledge, most still rated their MEP systems knowledge as at least average. Students believed they had more slightly background knowledge of and were more proficient working with architectural systems versus working with MEP systems. BIM-based architectural system instruction appeared to students to provide more opportunities to gain additional knowledge than BIM-based instruction for MEP systems.

Figure 5. Self-reported level of previous knowledge background.

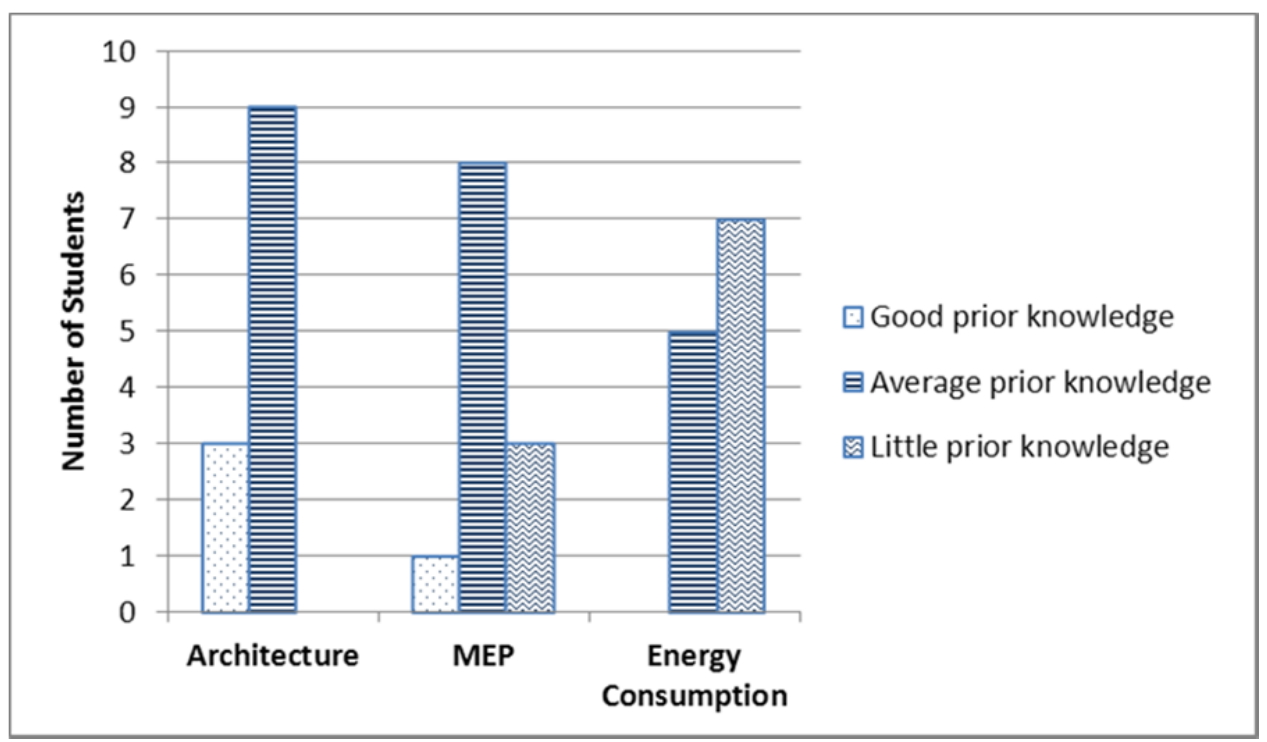

\section{Conclusions}

Results indicated that BIM coupled with building energy analysis software and used with PBL, provided a good pedagogical as well as a suitable technical platform for teaching sustainability in a building design and construction class. The majority of students found BIM-PBL to be an effective knowledge enhancement tool. Results also indicated that most students believe the energy analysis software package (Ecotect) helped them to better understand building energy consumption. Due to the pilot nature and small number of students involved in this study, these conclusions need to be confirmed by larger-scale studies.

The outcomes from the students' term project and the results of the survey provide positive evidence of the effectiveness of using BIM as a platform for building systems instruction while simultaneously teaching concepts relevant to building sustainability. Students did not, however, indicate a pronounced preference for a BIM-PBL type of course versus the more traditional concept based sustainability course.

A majority of students in this study believed they enrolled in the BIM course with a stronger previous knowledge of architectural systems than MEP systems. Previous levels of knowledge may correspond to areas of strength and weakness in each curriculum. More familiar material appears easier to learn, so it was not surprising that students believed that BIM was more effective for architectural systems, where three courses are required, versus MEP systems, where only one course is required by the local curriculum. Students should be expected to learn more from most forms of instruction when they possess additional prior knowledge about the subject material. This finding provides strong 
support for the argument that BIM should be taught as an advanced undergraduate course (maybe a technical elective during the senior year) versus as an introductory class [31,32].

\section{References}

1. Kevern, J.T. Green building and sustainable infrastructure: Sustainability education for civil engineers. J. Profession. Issues Eng. Educ. Pract. 2011, 137, 107-112.

2. Hall, G.M.; Howe, J. Sustainability of the chemical manufacturing industry-Towards a new paradigm? Educ. Chem. Eng. 2010, 5, 100-107.

3. Hokanson, D.; Phillips, L.D.; Mihelcic, J. Educating engineers in the sustainable futures model with a global perpective: Education, research \& diversity initiatives. Int. J. Eng. Educ. 2007, 23, 254-265.

4. Becerik-Gerber, B.; Gerber, D.J.; Ku, K. The pace of technological innovation in architecture, engineering, and construction education: Integrating recent trends into the curricula. J. Inf. Technol. Constr. 2011, 16, 411-432.

5. Jonassen, D.H. Instructional design models for well-structured and ill-structured problem-solving learning outcomes. Educ. Technol. Res. Dev. 1997, 45, 65-94.

6. Helle, L.; Tynjala, P.; Olkinuora, E. Project-based learning in post-secondary education-Theory, practice and rubber sling shots. High. Educ. 2006, 51, 287-314.

7. Lima, R.M.; Carvalho, D.; Flores, M.A.; van Hattum-Janssen, N. A case study on project led education in engineering: Students' and teachers' perceptions. Eur. J. Eng. Educ. 2007, 32, $337-347$.

8. Fernandes, S.; Flores, M.A.; Lima, R.M. Students' views of assessment in project-led engineering education: Findings from a case study in Portugal. Assess. Eval. High. Educ. 2012, 37, 163-178.

9. Frank, M.; Lavy, I.; Elata, D. Implementing the project-based learning approach in an academic engineering course. Intl. J. Technol. Des. Educ. 2003, 13, 273-288.

10. Eastman, C.; Teicholz, P.; Sacks, R.; Liston, K. BIM Handbook; Wiley \& Sons: Hoboken, NJ, USA, 2008.

11. Bazjanac, V. IFC BIM-based methodology for semiautomatic building energy performance simulation. In Proceedings of CIB W78 25th Conference on Information Technology in Construction: Improving the Management of Construction Projects through IT Adoption, Santiago, Chile, 15-17 July 2008; Rischmoller, L., Ed.; Universidad de Talca: Talca, Chile; pp. 292-299; ISBN 978-956-319-361-9.

12. Azhar, S.; Brown, J.; Farooqui, R. BIM-based sustainability analysis: An evaluation of building performance analysis software. In Proceedings of the 45th ASC Annual Conference, Gainesville, FL, USA, 1-4 April 2009.

13. Wang, E.; Shen, Z.; Berryman, C. A building LCA case study using Autodesk Ecotest and BIM model. In Proceedings of the 47th ASC Annual International Conference, Omaha, NE, 6-9 April 2011.

14. U.S. Department of Energy. EnergyPlus Energy Simulation Software; U.S. Department of Energy: Washington, USA. Available online: http://apps1.eere.energy.gov/buildings/energyplus (accessed on 20 March 2012). 
15. Ku, K.; Mahabaleshwarkar, P.S. Building interactive modeling for construction education in virtual worlds. J. Inf. Technol. Constr. 2011, 16, 189-208.

16. Jonassen, D.H.; Peck, K.L.; Wilson, B.G. Learning with Technology: A Constructivist Perspective; Prentice-Hall Inc.: Upper Saddle River, NJ, USA, 1999.

17. Thomas, J.W. A Review of Research on Project-based Learning; Technical Report for Autodesk Foundation: San Rafael, CA, USA, March 2000.

18. Mills, J.E.; Treagust, D.F. Engineering education-Is problem-based or project-based learning the answer? Australasian J. Eng. Educ. 2003. Available online: www.aaee.com.au/journal/2003/ mills_treagust03.pdf (accessed on 20 March 2012).

19. Dym, C.; Agogino, A.; Eris, O.; Frey, D.; Leifer, L. Engineering design thinking, teaching, and learning. J. Eng. Educ. 2005, 94, 103-120.

20. Dunlap, J. Problem-based learning and self-efficacy: How a capstone course prepares students for a profession. Educ. Technol. Res. Dev. 2005, 53, 65-85.

21. Brunetti, A.J.; Petrell, R.J.; Sawada, B. SEEDing sustainability: Team project-based learning enhances awareness of sustainability at the University of British Columbia, Canada. Int. J. Sustain. High. Educ. 2003, 4, 210-217.

22. Shephard, K. Higher education for sustainability: Seeking affective outcomes. Int. J. Sustain. High. Educ. 2007, 9, 87-98.

23. Walker, J.B.; Seymour, M.W. Utilizing the design charrette for teaching sustainability. Int. J. Sustain. High. Educ. 2008, 9, 157-169.

24. Brundiers, K.; Wiek, A.; Redman, C.L. Real-world learning opportunities in sustainability: From classroom into the real world. Int. J. Sustain. High. Educ.2010, 11, 308-324.

25. Kumar, S. Interoperability between Building Information Models (BIM) and Energy Analysis Programs. Master's Thesis, University of Southern California, Los Angeles, CA, USA, 2008.

26. Johnson, B.T.; Gunderson, D.E. Educating students concerning recent trends in AEC: A survey of ASC member programs. In Proceedings of the 46th ASC Annual International Conference, Boston, Massachusetts, USA, 7-10 April 2010.

27. Peterson, F.; Hartmann, T.; Fruchter, R.; Fischer, M. Teaching construction project management with BIM supports: Experience and lessons learned. Autom. Constr. 2010, 20, 115-125.

28. Richards, E.; Clevenger, C. Interoperable learning leveraging building information modeling (BIM) in construction management and structural engineering education. In Proceedings of 47th ASC Annual International Conference, Omaha, NE, USA, 6-9 April 2011.

29. Shen, Z.; Issa, R. Quantitative evaluation of the BIM-assisted construction detailed cost estimates. J. Inf. Technol. Constr. 2010, 15, 234-257.

30. Wong, K.A.; Wong, K.F.; Nadeem, A. Building information modelling for tertiary construction education in Hong Kong. J. Inf. Technol. Constr. 2011, 16, 467-476.

31. Taylor, J.; Liu, J.; Hein, M. Integration of building information modeling (BIM) into an ACCE accredited construction management curriculum. In Proceedings of the 44th ASC Annual International Conference, Auburn, AL, USA, 2-5 April 2008; pp. 117-124.

32. Sacks, R.; Barak, R. Teaching building information modeling as an integral part of freshman year civil engineering education. J. Profession. Issues Eng. Educ. Pract. 2010, 136, 30-38. 
33. Wang, L.; Gwilliam, J.; Jones, P. Case study of zero energy house design in UK. Energy Build. 2009, 41, 1215-1222.

34. Issa, R.; Suermann, P.C.; Olbina, S. Use of building information models in simulations. In Proceedings of the Winter Simulation Conference, Austin, TX, USA, 13-16 December 2009; pp. 2664-2671.

35. Wang, E.; Shen, Z.; Barryman, C. A building LCA case study using Autodesk Ecotect and BIM model. In Proceedings of the 47th ASC Annual International Conference, Omaha, NE, USA, 6-9 April 2011.

\section{Appendix A Survey: What you learn from BIM}

1. Creating BIM models (Architectural) helped you to better understand architectural systems (wall, foundation, floor, roof, etc.).
a. agree
b. disagree
c. neutral

2. Creating BIM models (MEP) helped you to better understand MEP system (air terminals, duct, AHU, condenser, plumbing, drainage systems, etc.).
a. agree
b. disagree
c. neutral

3. Ecotect helped you to better understand how building systems affect energy consumptions.
a. agree
b. disagree
c. neutral

4. By 3D Architectural modeling in BIM, you gained better understanding or new knowledge in which particular architectural systems (you can select multiple answers as applied)?
a. Wall system
b. structural system
c. floor system
d. roof system
e. overall building system
f. none

5. By 3D MEP modeling in BIM, you gained better understanding or new knowledge in which particular MEP systems (you can select multiple answers as applied)?
a. AHU
b. Duct work
c. drainage system
d. vent system
e. cold water supply
f. hot water supply
g. Supply air
h. return air
i. exhaust air
j. fresh air
k. condenser
1. none

6. By 3D architectural modeling in BIM, you gained better understanding or new knowledge in which particular knowledge areas (you can select multiple answers as applied)?
a. The structure/layout of the arch. Systems
b. the functions of the arch. Systems
c. the behaviors of the systems d. none

7. By 3D MEP modeling in BIM, you gained better understanding or new knowledge in which particular knowledge areas (you can select multiple answers as applied)?
a. The structure/layout of the arch. Systems
b. the functions of the arch. Systems
c. the behaviors of the systems
d. none

8. Modeling MEP help me to better understand the whole building system including architecture design.
a. agree
b. disagree
c. neutral 
9. Ecotect thermal analysis using 3D BIM model helped me to better understand how heating/cooling loads are calculated.
a. agree
b. disagree
c. neutral

10. Using an actual building and energy consumption data in project give me more motivation to do the project.
a. agree
b. disagree
c. neutral

11. Without doing the architectural BIM modeling I feel I can learn similar knowledge in different classes
a. agree
b. disagree
c. neutral

12. Without doing the MEP BIM modeling I feel I can learn similar knowledge in different classes
a. agree
b. disagree
c. neutral

13. Which of the following is an accurate description of your prior knowledge in Architecture?

a. I already had good knowledge of Arch. Systems

b. I had average knowledge of Arch. Systems

c. I had little knowledge of Arch. Systems

14. Which of the following is an accurate description of your prior knowledge in MEP?

a. I already had good knowledge of MEP

b. I had average knowledge of MEP

c. I had little knowledge of MEP

15. Which of the following is an accurate description of your prior knowledge in energy consumption?

a. I already had good knowledge of energy consumption

b. I had average knowledge of energy consumption

c. I had little knowledge of energy consumption

(C) 2012 by the authors; licensee MDPI, Basel, Switzerland. This article is an open access article distributed under the terms and conditions of the Creative Commons Attribution license (http://creativecommons.org/licenses/by/3.0/). 